\title{
Algoritma Menghadang Bola dengan Metode Fuzzy Logic untuk Robot Penjaga Gawang Sepak Bola Beroda
}

\author{
Kamal Arief, Djoko Purwanto, dan Hendra Kusuma \\ Departemen Teknik Elektro, Fakultas Teknologi Elektro, Institut Teknologi Sepuluh Nopember (ITS) \\ e-mail: kamalarief17@gmail.com
}

\begin{abstract}
Abstrak-Robot sepak bola beroda adalah suatu robot yang bekerja secara tim untuk melakukan permainan sepak bola. Peran penjaga gawang dalam permainan ini sangat vital karena merupakan pertahanan terakhir sebelum mendapatkan gol. Oleh karena itu, perlu penjagaan yang responsif dalam menghadang bola. Untuk mendapatkan penghadangan bola yang responsif metode Fuzzy Logic dapat diterapkan disini. Input Fuzzy Logic dalam penelitian ini berupa sudut bola terhadap robot dan kecepatan pergerakan bola. Dengan mengetahui sudut bola terhadap robot kita akan mendapatkan orientasi pergerakan robot tersebut menuju bola. Lalu, dengan mengetahui kecepatan bola kita akan mendapatkan kecepatan robot yang diperlukan untuk menghadang bola dengan tepat. Robot penjaga gawang pada Studi kali ini menggunakan robot dari Tim Robot Sepak Bola Beroda ITS. Pengujian dalam penelitian ini untuk mengetahui respon robot dalam menghadang bola pada setiap tendangan. Pada hasil pengujian yang dilakukan robot telah berhasil menghadang bola dengan tepat, dari 50 percobaan tendangan, robot ini dapat menghadang 38 tendangan. Persentase penyelamatan yaitu 76\%. Dari data sudut bola, kecepatan pergerakan bola dan keluaran dari metode fuzzy sesuai dengan rule yang direncanakan.
\end{abstract}

Kata Kunci-Robot Penjaga Gawang, Menghadang Bola, Fuzzy Logic.

\section{PENDAHULUAN}

$\mathrm{R}$ OBOT adalah alat yang dapat membantu banyak kebutuhan manusia secara fisik baik dengan kontrol oleh manusia ataupun secara otomatis dengan program yang telah ditanamkan terlebih dahulu pada robot. Untuk memacu pengembangan pengethuan tentang robot, ada banyak sekali kontes yang diadakan setiap tahunnya dengan tema-tema yang beraneka ragam. Salah satu kontes yang tersebut adalah Kontes Robot Sepak Bola Indonesia kategori beroda.

Salah satu tantangan dari divisi robot ini adalah menghalau bola agar tidak masuk ke gawang. Tugas ini dilakukan oleh robot penjaga gawang. Banyak metode yang dapat disinggung tentang robot penjaga gawang ini. Salah satunya adalah algoritma menghalau bola dan metode untuk menghalaunya. Disini saya akan menggunakan Fuzzy Logic setelah menimbang beberapa metode yang pas dalam menghalau bola tersebut.

Dengan menggunakan kamera dengan sudut pandang 360 derajat tentunya akan membuat sudut pandang robot terhadap lingkungan semakin luas sehingga tidak diperlukan lagi terlalu banyak gerakan mekanik untuk mencari bola sehingga robot dapat lebih cepat untuk menentukan keputusan selanjutnya.

Kamera akan menghasilkan citra lingkuangan yang jika diproses lebih lanjut akan mendapatkan posisi bola pada citra. Posisi bola pada citra dapat di representasikan dengan x, y dari bola dengan satuan pixel. Namun posisi $\mathrm{x}$, y bola pada citra tidak linear terhadap posisi sesungguhnya terhadap robot sehingga diperlukan proses pengolahan lebih lanjut untuk mendapatkan posisi bola terhadap robot. Beberapa metode yang dapat digunakan adalah Jaringan Saraf tiruan atau regresi polinomial.

Data posisi bola tersebut akan saya sampling selama waktu tertentu untuk mendapatkan data kecepatan dan sudut bola terhadap robot. Data-data ini yang selanjutnya akan menjadi masukkan fuzzy yang kemudian akan masuk ke pengkategorian membership function dalam prosedur Fuzzification. Data yang sudah dikelompokkan akan masuk ke Rule Set dan akan mengeluarkan suatu statement sesuai rulebase yang telah ditentukan yang selanjutnya masuk ke proses Defuzzification yang menghasilkan output yang akan masuk proses selanjutnya. Output dari Fuzzy Logic tersebut yaiti kecepatan pergerakan robot dan posisi robot terhadap sumbu X lapangan.

\section{URAIAN PENELITIAN}

\section{A. Logika Fuzzy}

Logika Fuzzy adalah suatu metode kecerdasan buatan yang dikenalkan pertama kali oleh Lothfi A. Zadeh pada tahun 1965 [1]. Inti dari Logika Fuzzy adalah memetakan ruang input ke ruang output. Mekanisme utama untuk melakukannya adalah pernyataan if-then yang disebut aturan. Semua aturan dievaluasi secara paralel dan tidak memperhatikan urutannya. Aturan tersebut merujuk pada variabel dan kata sifat yang menggambarkan variabel-variabel tersebut. Sebelum membangun sistem dan menafsirkan aturannya, perlu ditentukan semua istilah yang akan direncanakan untuk digunakan dan kata sifat yang menggambarkan keadaannya. Sebagai contoh, untuk menentukan bahwa robot dapat berjalan "cepat", harus ditentukan kisaran kecepatan robot yang bervariasi dan memenuhi maksud dengan kata "cepat".

\section{B. Himpunan Fuzzy}

Himpunan fuzzy dapat diartikan sebagai suatu kelas bilangan dalam suatu batasan yang samar. Pada himpunan fuzzy nilai keanggotaan bernilai 0 sampai 1 .

Himpunan fuzzy memiliki 2 atribut, yaitu :

1) Linguistik 
Penamaan suatu grup yang mewakili suatu keadaan atau kondisi tertentu dengan menggunakan bahasa alami, seperti : Muda, Parobaya, Tua.

2) Numeris

Suatu nilai (angka) yang menunjukkan ukuran dari suatu variabel seperti : $15,50,70$.

\section{Fungsi Keangotaan}

Fungsi keanggotaan adalah suatu himpunan input data yang direpresentasikan dalam sebuah fungsi yang bernilai 0 sampai 1 atau kata lain fungsi keangotaan merepresentasikan derajart keanggotaan dalam logika fuzzy.

Ada beberapa representasi dari fungsi keanggotaan, yaitu:

1) Representasi linear

Pada representasi linear, pemetaan input ke derajat keanggotaannya digambarkan sebagai suatu garis lurus. Bentuk ini paling sederhana dan menjadi pilihan yang baik untuk mendekati suatu konsep fuzzy.

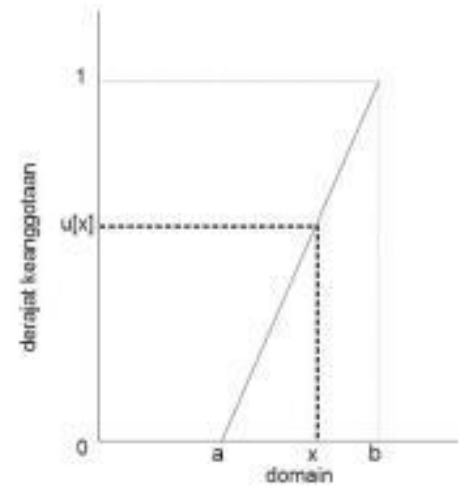

Gambar 1. Representasi linear naik.

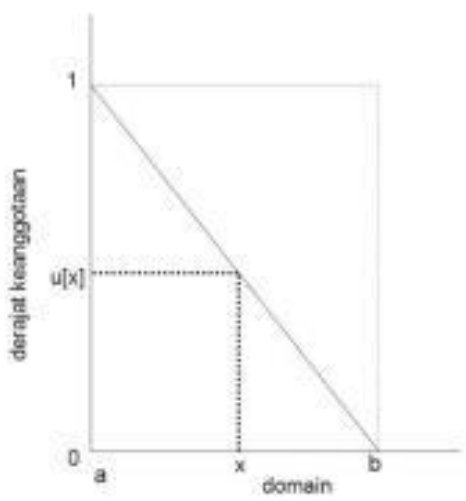

Gambar 2. Representasi linear turun.

Pada representasi linear naik, perhitungan derajat keanggotaannya yaitu sebagai berikut:

$$
\mu[x]=\left\{\begin{array}{cc}
0, & \text { lainnya } \\
\frac{(x-a)}{(b-a)}, & a \leq x \leq b \\
1, & x>b
\end{array}\right.
$$

Pada representasi linear turun, perhitungan derajat keanggotaannya yaitu sebagai berikut:

$$
\mu[x]=f(x)=\left\{\begin{array}{cl}
0, & \text { lainnya } \\
\frac{(b-x)}{(b-a)}, & a \leq x \leq b
\end{array}\right.
$$

2) Representasi segitiga

Representasi segitiga adalah gabungan antara 2 garis linear.

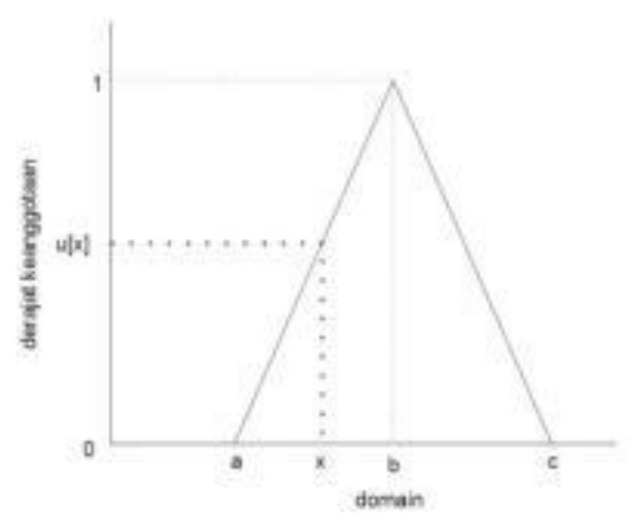

Gambar 3. Representasi segitiga.

Pada representasi segitiga, perhitungan derajat keanggotaannya yaitu sebagai berikut:

$$
\mu[x]=\left\{\begin{array}{lc}
0, x<a \text { atau } x>c \\
\frac{(x-a)}{(b-a)}, & a \leq x \leq b \\
\frac{(b-x)}{(c-b)}, & b \leq x \leq c
\end{array}\right.
$$

Kita dapat memilih berbagai macam fungsi keanggotaan, namun harus tetap dipilih sesuai kebutuhan kita. Kita harus bisa memperkirakan bahwa sistem butuh nilai yang beragam atau tidak tergantung kebutuhannya.

\section{Sistem Inferensi Fuzzy}

Sistem inferensi fuzzy merupakan proses pengolahan data dalam bentuk crisp input yang melalui beberapa tahapan dalam sistem fuzzy untuk menghasilkan data dalam bentuk crips output. Terdapat tiga metode sistem inferensi fuzzy, yaitu: Mamdani, Sugeno dan Tsukamoto. Tahap sistem inferensi fuzzy yang harus dilalui, yaitu :

\section{1) Nilai Input}

Berupa masukan dalam bentuk nilai pasti (crisp).

\section{2) Fuzzifikasi}

Proses merubah crisp input menjadi fuzzy menggunakan fungsi keanggotaan, setiap variabel fuzzy dimodelkan ke dalam fungsi keanggotaan yang dipilih.

\section{3) Aturan - aturan (rules)}

Aturan-aturan yang akan dijadikan dasar untuk mencari nilai dari crisp output yang akan dihasilkan.

4) Defuzzifikasi

Merupakan proses merubah kembali data yang dijadikan fuzzy ke dalam bentuk crisp kembali.

5) Nilai output

Merupakan hasil akhir yang dapat dipakai untuk pengambilan keputusan. Namun terkadang sistem fuzzy dapat berjalan tanpa harus melalui komposisi atau dekomposisi fuzzy. Nilai output dapat diestimasi secara langsung dari nilai keanggotaan yang berhubungan dengan antesedennya.

\section{E. Metode Tsukamoto}

Dalam metode Tsukamoto, tiap konsekuen pada aturan yang berbentuk if-then harus direpresentasikan dengan suatu himpunan fuzzy dengan fungsi keanggotaan yang monoton. Hasilnya, output inferensi yang dihasilkan dari tiap-tiap aturan diberikan secara tegas(crisp) berdasar o-predikat. Hasil akhirnya diperoleh dengan rata-rata terbobot [2]. 

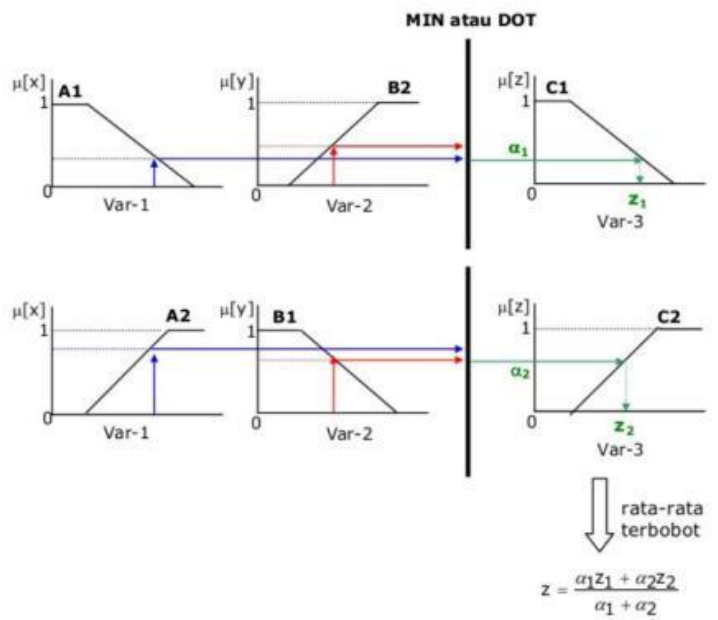

Gambar 2. Inferensi Fuzzy dengan metode Tsukamoto [2].

\section{F. $\quad$ Kamera Omnidireksional}

Gambar II. Kamera Omnidireksional.

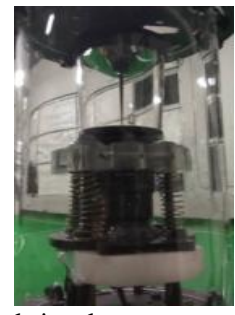

Dalam fotografi omnidireksional kamera adalah sebuah kamera yang memiliki sudaut pandang 360 derajat pada area horizontal atau sudut pandang yang melingkupi hampir seluruh bola. Kamera omnidireksional digunakan pada fungsi yang memerlukan sudut pandang luas seperti pada fotografi panorama dan beberapa keperluan robotika. Dalam robotika, kamera omnidireksional sering digunakan untuk odometri secara visual dan untuk menyelesaikan simultaneous localization and mapping (SLAM). Karena kemampuan kamera omnidireksional untuk mengambil gambar dengan sudut pandang 360 derajat, hasil yang lebih baik akan didapatkan untuk optical flow dan feature selection and matching.

\section{G. Perancangan Sistem}

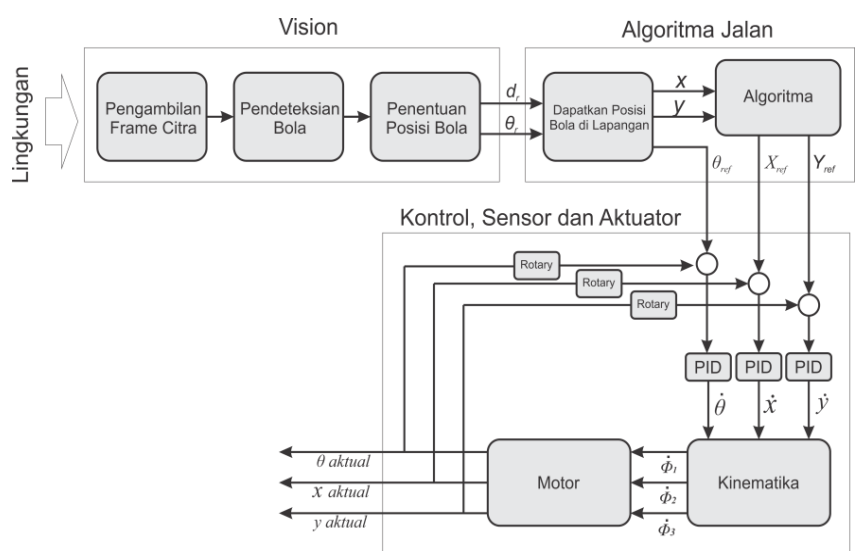

Gambar 3. Blok diagram sistem

Pada pernacangan robot penjaga gawang kali ini ada beberapa bagian penting yang saling berkaitan. Sistem ini terrepresentasikan dalam gambar blok diagram pada Gambar 3 pada blok tersebut.

\section{a. Vision}

Blok vision adalah hal utama dalam pengambilan data bola dan lapangan sepak bola lalu diolah agar didapatkan informasi posisi bola terhadap robot. posisi bola terhadap robot dinyatakan dalam koordinat polar yaitu jarak bola terhadap robot yang dinyatakan dalam $d_{r}$ dan sudut bola terhadap arah depan robot yang dinyatakan dalam $\theta_{r}$ dengan memosikan robot

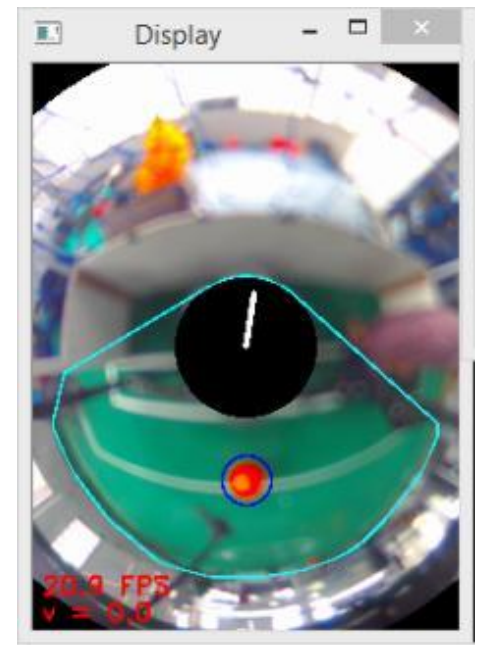

Gambar 8. Hasil Pendeteksian bola.

Pada tahap sebelumnya didapatkan informasi tentang posisi bola terhadap titik tengah pada citra. Namun jari-jari yang diperoleh pada informasi ini tidak merepresentasikan nilai jarak sesungguhnya. Hubungan antara jari-jari bola terhadap titik tengah pada citra dan jarak bola sesungguhnya terhadap robot juga tidak linear. Oleh karenanya diperlukan sebuah proses untuk menentukan posisi bola terhadap robot dari informasi yang ada. Salah satu pendekatan yang dilakukan yaitu dengan metode regresi polinomial.

Saat terdapat bola terdeteksi, posisi bola pada citra akan diketahui juga dengan melihat titik pusat bola pada citra. Diasumsikan posisi bola dari proses pendeteksian bola dinyatakan dengan $\mathrm{x}_{\mathrm{b}}$ dan $\mathrm{y}_{\mathrm{b}}$. Dan posisi tengah citra diasumsikan dengan $\mathrm{x}_{\mathrm{c}}$ dan $\mathrm{y}_{\mathrm{c}}$. Untuk menkonversi posisi tersebut menjadi jarak pusat bola terhadap titik tengah citra $\left(r_{p}\right)$ dan sudut bola terhadap titik tengah $(\theta)$ citra digunakan persamaan berikut:

$$
\begin{gathered}
r_{p}=\sqrt{\left(x_{b}-x_{c}\right)^{2}+\left(y_{b}-y_{c}\right)^{2}} \\
\theta=\tan ^{-1} \frac{\left(y_{0}-y_{c}\right)}{-\left(x_{0}-x_{c}\right)}
\end{gathered}
$$

Pada tahap selanjutnya kita akan mencari kecepatan bola. Kecepatan bola disini kita cari dengan cara sampling perpindahan bola tiap $150 \mathrm{~ms}$, perpindahan ini terdari 2 sumbu, yaitu sumbu x dan sumbu y. titik awal bola kita dapat sebut sebagai $x_{0}$ dan $y_{0}$, titik akhir bola saat sampling selanjutnya dapat kita sebut $x_{1}$ dan $y_{1}$. Setelah titik tersebut didapatkan kita selanjutnya mencari selisih dari kedua titik tersebut. Selisih dari kedua titik tersebut dapat kita sebut sebagai vektor kecepatan tiap sumbu. Setelah mendapatkan vektor kecepatan tiap sumbu, selanjutnya akan didapatkan resultan dari kecepatan denga metode phytagoras. Data 
resultan ini kita gunakan sebagai data kecepatan bola yang digunakan sebagai input fuzzy, lalu ketika penjaga gawang merespon bola dan bergerak sesuai output fuzzy (z)yang bergerak hanya terhadap sumbu x lapangan maka kecepatan relative bola akan berbeda dari yang seharusnya, maka perlu ada pertambahan di vector kecepatan $\mathrm{x}$ yang ditambah dengan kecepatan gerak robot terhadap sumbu-x. Alur persamaan dengan pseudocode dan ilustrasinya dapat kita lihat di persamaan dibawah.

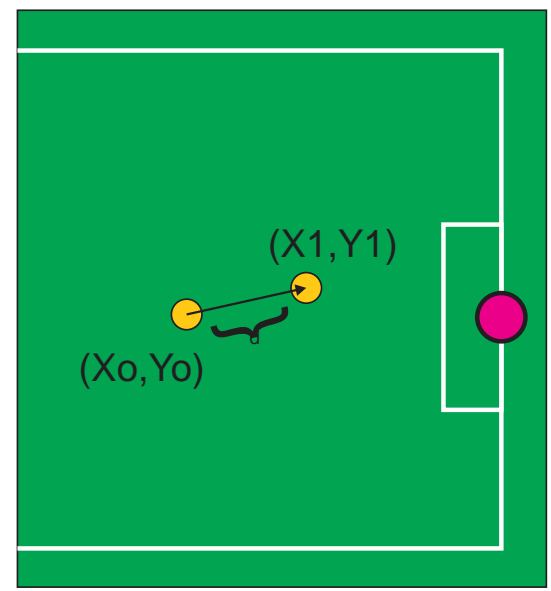

Gambar 5. Ilustrasi mendapatkan kecepatan bola.

\section{Pseudocode:}

time = ofGetSystemTime);

Iftime - timeprev $<150)$

\{

$$
\begin{aligned}
& V x=x_{1}-x_{0}+z \\
& V y=y_{1}-y_{0} \\
& \text { Vresultan }=\sqrt{V x^{2}+V y^{2}} \\
& \text { if }(V y<0) \\
& \{ \\
& \text { Vresultan }=\text {-Versultan } \\
& \quad\} \\
& \text { else Vresultan = Versultan } \\
& \text { timprev }=\text { time } \\
& x_{1}=x_{0} \\
& y_{1}=y_{0}
\end{aligned}
$$$$
\text { \} }
$$

\section{b. Perencanaan Fuzzy Logic}

Pada subbab ini akan membahas komponen apa saja ang diperlukan untuk menjalankan algoritma fuzzy logic. Perencanaan ini meliputi fungsi keanggotaan tiap variable input, perencanaan rule dan perencanaan keluaran fuzzy yang diinginkan.

\section{i. Perancangan Fungsi Keangotaan}

Dalam Studi ini, setiap variabel fuzzy menggunakan fungsi keanggotaan bahu, linier turun, linier naik, trapezoid dan segitiga sebagai pendekatan untuk memperoleh derajat keanggotaan suatu nilai dalam suatu himpunan fuzzy. Bentuk kurva berikut ini adalah kurva default dari beberapa faktor yang mempengarui himpunan-himpunannya.

\section{a. Fungsi Keangotaan Sudut Bola}

Pada Variabel Sudut Bola ada 3 macam himpunan fuzzy yaitu: KECIL, AGAK KECIL, SEDANG, AGAK BESAR, BESAR. Himpunan KECIL memiliki pendekatan fungsi keangotaan linier turun bahu kiri, Himpunan AGAK KECIL, AGAK BESAR menggunakan pendekatan fungsi keangotaan segitiga, untuk Himpunan SEDANG menggunakan fungsi keangotaan trapesium. untuk himpunan BESAR menggunakan pendekatan fungsi keangotaan linier naik bahu kanan.

u Sudut Bola

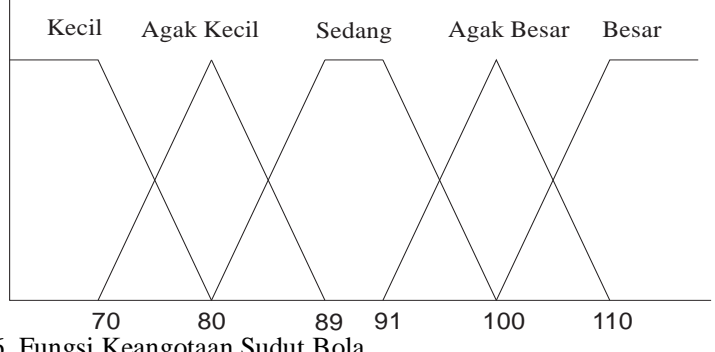

Gambar 6. Fungsi Keangotaan Sudut Bola

b. Fungsi Keangotaan Kecepatan Bola

Pada variabel sudut bola ada 3 macam himpunan fuzzy yaitu: lambat, agak lambat, sedang, agak cepat, cepat. Himpunan lambat memiliki pendekatan fungsi keangotaan linier turun bahu kiri, himpunan agak lambat, agak cepat menggunakan pendekatan fungsi keangotaan segitiga, untuk himpunan cepat menggunakan pendekatan fungsi keangotaan linier naik bahu kanan.

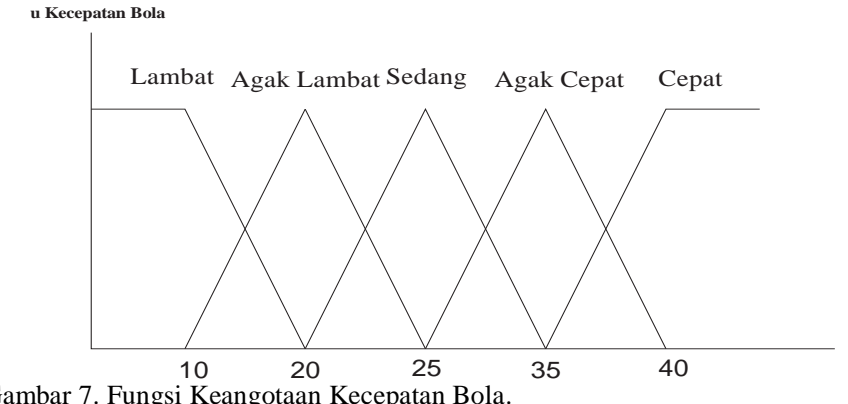

Gambar 7. Fungsi Keangotaan Kecepatan Bola.

\section{ii. Perancangan Rule}

\begin{tabular}{|c|c|c|c|c|c|}
\hline Sudut IIV & Lambat & $\begin{array}{l}\text { Agak } \\
\text { Lambat }\end{array}$ & Sedang & $\begin{array}{l}\text { Agak } \\
\text { Cepat }\end{array}$ & Cepat \\
\hline & Kanan & $\begin{array}{l}\text { Kanan } \\
\text { Agak }\end{array}$ & Kanan & Kanan & Kanan \\
\hline Kecil & Sedang & Cepat & $\begin{array}{l}\text { Cepat } \\
\text { Kanan }\end{array}$ & Cepat & Cepat \\
\hline Agak & Kanan & Kanan & Agak & Kanan & Kanan \\
\hline Kecil & Lambat & Sedang & Cepat & Cepat & Cepat \\
\hline Sedang & Diam & Diam & $\begin{array}{l}\text { Diam } \\
\text { Kiri }\end{array}$ & Diam & Diam \\
\hline Agak & Kiri & Kiri & Agak & Kiri & Kiri \\
\hline \multirow[t]{2}{*}{ Besar } & Lambat & Sedang & Cepat & Cepat & Cepat \\
\hline & Kiri & Kiri Agak & Kiri & Kiri & Kiri \\
\hline Besar & Sedang & Cepat & Cepat & Cepat & Cepat \\
\hline
\end{tabular}

Berisi tentang aturan-aturan yang berlaku untuk semua kejadian (kombinasi). Proses ini berfungsi untuk mencari suatu nilai fuzzy output dari fuzzy input. Prosesnya adalah sebagai berikut: suatu nilai fuzzy input yang berasal dari proses fuzzyfikasi kemudian dimasukkan kedalam sebuah rule yang telah dibuat untuk dijadikan sebuah fuzzy output. Berikut ini adalah Rule yang akan digunakan untuk perhitungan fuzzy:

Tabel 1 .

Rule Fuzzy 


\section{PENGUJIAN DAN PEMBAHASAN}

Pada bab ini berisi tentang pengujian dari sistem yang telah dibuat. Pengujian ini bertujuan untuk mengetahui tingkat ketercapaian tujuan dari sistem yang dirancang.

\section{A. Uji Jarak Bola Terhadap Robot}

Sebelum mendapatkan kecepatan dan sudut bola kita harus mencari posisi bola terhadap robot. Lalu setelah menemukan jarak tersebut kita dapat menemukan posisi bola pada lapangan. Berikut data hasil pengukuran tersebut. Data tersebut akan masuk ke regresi polinomial agar data pixel dapat sama dengan jarak dalam meter.

Tabel 2

Tabel Jarak Bola Terhadap Robot

\begin{tabular}{lllc}
\hline \hline $\begin{array}{l}\text { Input } \\
\text { (pixel) }\end{array}$ & $\begin{array}{l}\text { Output } \\
\text { (meter) }\end{array}$ & $\begin{array}{l}\text { Perhitungan } \\
\text { Output }\end{array}$ & Error \\
\hline 128 & 50 & 49,79548876 & 0,2045112389 \\
170 & 100 & 101,3221991 & 1,322199056 \\
197 & 150 & 147,9076201 & 2,092379933 \\
212 & 200 & 200,8446555 & 0,8446554676 \\
221 & 250 & 246,5678476 & 3,432152372 \\
230 & 300 & 305,0351495 & 5,035149497 \\
236 & 350 & 352,0119497 & 2,01194968 \\
241 & 400 & 396,5150898 & 3,484910176 \\
Rata-Rata Error & & 2,303488428 \\
\hline \hline
\end{tabular}

Didapatkan persamaan regresi polonomial orde-2 dari data input ke data output sebagai berikut.

$$
y=0,0004 x^{3}-0,2033 x^{2}+33,292 x-1772,9
$$

Data dari pengujian pendeteksian bola direpresentasikan pada grafik berikut ini:

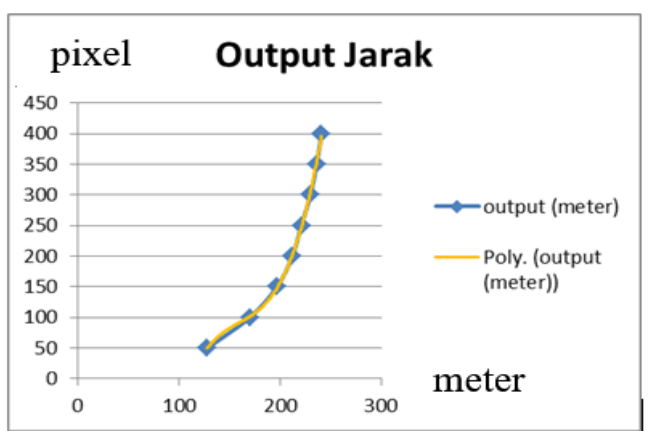

Gambar 8. Uji Pendeteksian Bola.

Dari percobaan ini, sistem mampu $50 \mathrm{~cm}$ sampai dengan $400 \mathrm{~cm}$. Dari grafik diatas antara input dan output hasil perhitungan hampir mendekati.

\section{B. Pengujian Jalan Algoritma}

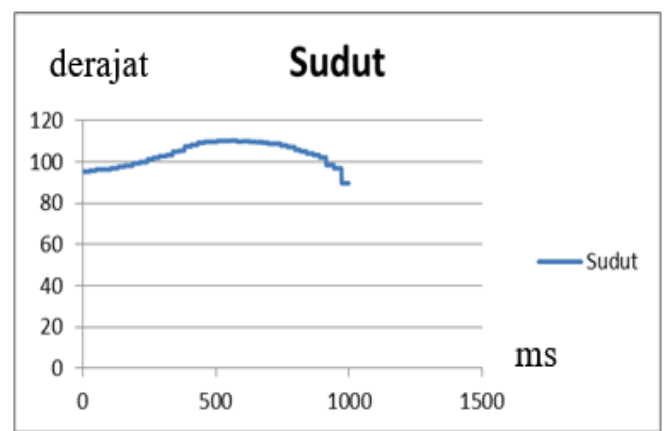

Gambar 9. Plot Sudut Bola terhadap Robot.
Pada pengujian jalan menggunakan algoritma Fuzzy ada 3 pecobaan tendangan yang dilakukan. Tiap tendangan ditendang dengan arah yang berbeda. Tendangan pertama ditendang melalui tengah lapangan ke tengah gawang, tendangan kedua ditendang dari tengah lapangan ke kanan gawang. Tendangan ke 3 ditendang dari tengah lapangan menuju kiri gawang. Berikut adalah salah satu hasil plot data sudut bola, kecepatan bola dan output fuzzy dari salah satu tendangan.

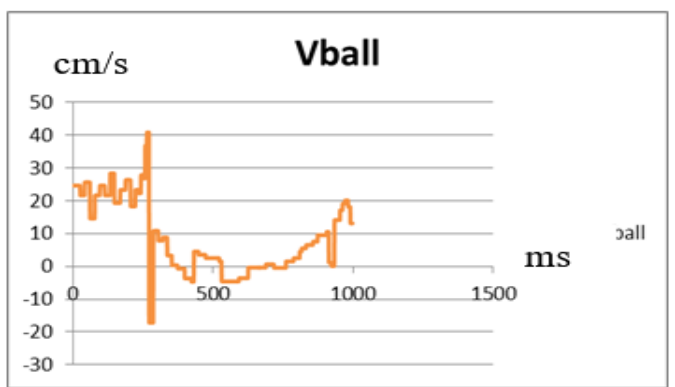

Gambar 10. Plot Kecepatan Bola.

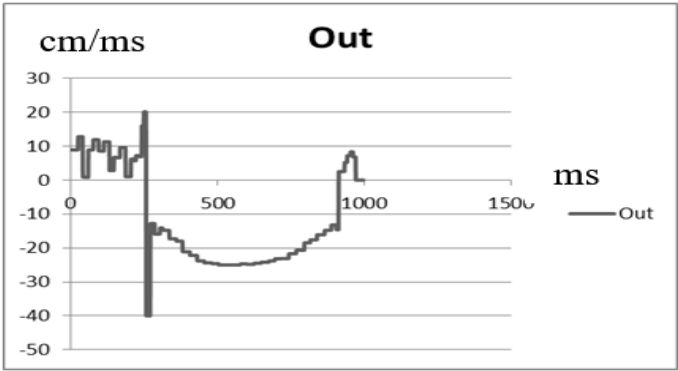

Gambar 11. Plot Output Fuzzy.

\section{KESIMPULAN DAN SARAN}

\section{A. Kesimpulan}

Kesimpulan yang dapat diambil oleh penulis dari serangkaian pengujian yang telah dilakukan adalah sebagai berikut:

1. Metode penghadangan bola dengan metode Fuzzy Logic pada penjaga gawang sepak bola beroda dapat menyelamatkan tendangan kearah gawang dengan persentase $70 \%$.

2. Pendeteksian bola menggunakan kamera omni direksional dapat mendeteksi bola pada jarak $50 \mathrm{~cm}-400 \mathrm{~cm}$. metode mengkonversi jarak dalam pixel ke meter menggunakan metode regresi polinomial orde-3 dapat mendekati jarak yang diinginkan. Kesalahan yang terjadi pada pembacaan memiliki rata-rata sebesar 2,3\%.

\section{B. Saran}

Beberapa saran yang dapat diberikan penulis untuk pengembangan Studi ini adalah sebagai berikut:

1. Untuk pendeteksian kecepatan menggunakan metode yang lebih baik dan kamera dengan kecepatan penangkapan gambar yang lebih tinggi agar data kecepatan bola tidak terjadi glitch atau loncatan error data yang tinggi.

2. Input metode Fuzzy Logic yang digunakan menggunakan input lain yang lebih mudah dan lebih cepat didapatkan, agar waktu pemrosesan bisa lebih cepat.

3. Penggunaan data sudut bola terhadap robot juga dirasa kurang cocok untuk keadaan tertentu, seperti posisi bola saat 
ditendang dari kiri lapangan. Robot akan menuju ke posisi bola di kiri lapangan dahulu dalam mengejar bola, setelah bola bergerak lebih cepat robot akan mengejar kearah kiri dahulu hingga melewati sudut tengah robot, lalu akan bermanuver ke kanan sesuai arah dan kecepatan bola saat akan masuk ke gawang. Metode ini dirasa kurang efektif. Kedepannya seharusnya dapat digunakan metode perpotongan titik bola terhadap sumbu x gawang/garis gawang secara virtual dengan prediksi trayektori, agar robot tidak harus bergerak seperti metode yang digunakan sekarang.

\section{DAFTAR PUSTAKA}

[1] A. Kholili and Hamdan, "Sistem Informasi Spare Part Mobil Dengan Fasilitas Estimasi Stok Menggunakan Fuzzy Tsukamoto," Surabaya, 2012.

[2] S. Kusumadewi, Artificial Intelligence (Teknik dan Aplikasinya). Yogyakarta: Graha Ilmu, 2003. 